\title{
Measuring metaldehyde in surface waters in the UK using two monitoring approaches
}

\author{
Glenn D. Castle, ${ }^{a}$ Graham A. Mills, ${ }^{b}$ Adil Bakir, ${ }^{a}$ Anthony Gravell, ${ }^{c}$ Melanie Schumacher, ${ }^{c}$ Kate Snow ${ }^{d}$ \\ and Gary R. Fones*a \\ ${ }^{a}$ School of Earth and Environmental Sciences, University of Portsmouth, Burnaby Road, Portsmouth, \\ PO1 3QL, UK \\ ${ }^{b}$ School of Pharmacy and Biomedical Sciences, University of Portsmouth, White Swan Road, \\ Portsmouth, PO1 2DT, UK \\ 'Natural Resources Wales, NRW Analytical Services at Swansea University, Faraday Building, \\ Swansea University, Singleton Campus, Swansea, SA2 8PP, UK \\ ${ }^{d}$ United Utilities, Haweswater House, Lingley Mere Business Park, Lingley Green Avenue, Great \\ Sankey, Warrington WA5 3LP, UK
}

\begin{abstract}
Metaldehyde is a molluscicide and the active ingredient in formulated slug pellets used for the protection of crops. Due to its mobility in the environment it is frequently found in river catchments, often at concentrations exceeding the EU Drinking Water Directive limit of $100 \mathrm{ng} \mathrm{L}^{-1}$ for a single pesticide. This presents a major problem for water companies in the UK where such waters are abstracted for production of potable drinking water supplies. Therefore, it is important to understand the sources, transport and fate of this emerging pollutant of concern in the aquatic environment. We monitored metaldehyde in two contrasting river catchments (River Dee ( 8 sites) and River Thames (6 sites)) over a twelve-month period that coincided with the agricultural application period of the molluscicide. Spot samples of water were collected typically weekly or fortnightly. Chemcatcher ${ }^{\circ}$ passive samplers were deployed consecutively every two weeks. At the River Dee, there was little variability in the concentrations of metaldehyde $\left(<10-110 \mathrm{ng} \mathrm{L}^{-1}\right)$ measured in the spot samples of water. The Chemcatcher gave similar time-weighted average concentrations which were higher following increased rain fall events. At the River Thames, concentrations of metaldehyde varied more widely $\left(<9-4200 \mathrm{ng} \mathrm{L}^{-1}\right)$ with several samples exceeding $100 \mathrm{ng} \mathrm{L}^{-1}$. Generally, these concentrations were reflected in the time-weighted average concentrations obtained using the Chemcatcher ${ }^{\circ}$. Both monitoring techniques gave complementary data for identifying input sources, and in the development of catchment management plans and environmental remediation strategies.
\end{abstract}

\section{Introduction}

Metaldehyde $\left(\mathrm{C}_{8} \mathrm{H}_{16} \mathrm{O}_{4}\right.$, a non-chiral tetramer of acetaldehyde) is the active ingredient in most proprietary forms of slug pellets used to protect crops such as cereals, oilseed rape and potatoes. ${ }^{1,2}$ The amount of metaldehyde used in pellets is either $1.5,3.0,4.0$ or $5.0 \%$ by weight. ${ }^{3}$ In the United Kingdom, it is estimated that $80 \%$ of arable farmers use metaldehyde, with approximately $1640 \mathrm{t}$ being used in Great Britain between 2008 and 2014. ${ }^{4}$ The maximum allowable application is $700 \mathrm{~g}$ of metaldehyde per hectare per year. ${ }^{3}$ Metaldehyde is generally applied to land in the autumn and winter months when molluscs thrive in the wet weather conditions. ${ }^{5}$ Metaldehyde is a polar $\left(\log K_{\text {ow }}=0.12\right.$ at $20^{\circ} \mathrm{C}$ ), neutral molecule being highly water soluble and mobile in soil (Table 1). ${ }^{6}$ When applied to land, metaldehyde degrades in soil to acetaldehyde and then to $\mathrm{CO}_{2}$ and water, with a reported halflife varying between 3 and 223 days depending on environmental conditions. ${ }^{7,8}$ Once applied to land, it can run-off readily under wet conditions into field drains, gullies and surface waters. It is now considered as an emerging pesticide of concern. The impact of metaldehyde within the aquatic environment has been reviewed recently by Castle et $a l^{9}{ }^{9}$ 
Table 1. Chemical structure and physicochemical properties of metaldehyde

Structure

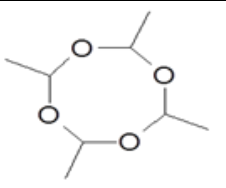

CAS number

108-62-3

IUPAC name

2,4,6,8-Tetramethyl-1,3,5,7-

tetraoxocane

Molar mass

$176.21 \mathrm{~g} \mathrm{~mol}^{-1}$

Boiling point

112 to $115^{\circ} \mathrm{C}$

Water solubility

$0.188 \mathrm{~g} \mathrm{~L}^{-1}$ at $20^{\circ} \mathrm{C}$

Vapour pressure

$0.66 \mathrm{mmHg}$ at $25^{\circ} \mathrm{C}$

Flash point

36 to $40^{\circ} \mathrm{C}$

Density

$1.27 \mathrm{~g} \mathrm{~cm}^{-3}$

Log octanol/water partition

0.12 at $20^{\circ} \mathrm{C}$

coefficient ( $\left.\log K_{\text {ow }}\right)$

$0.18-0.37$

Recent improvements in analytical techniques have allowed metaldehyde to be detected readily in river catchments in the UK, particularly those that run through intensively farmed arable land. ${ }^{10}$ These concentrations fluctuate with the seasonal application of the molluscicide. Often the concentration of metaldehyde exceeds the European Union's Drinking Water Directive limit of $100 \mathrm{ng}$ $\mathrm{L}^{-1}$ for any pesticide (also referred to within in the UK water industry as the prescribed concentration value (PCV) which is a legally binding limit). ${ }^{11}$ Although these concentrations of metaldehyde detected in surface water do not necessarily represent a direct risk to human health, ${ }^{9}$ they are a major concern where such surface water bodies are used as capitation sources for potable drinking water supplies. Due its physicochemical properties metaldehyde is difficult to remove from water using conventional (e.g. coagulation and filtration) drinking water treatment processes. Metaldehyde can be removed using advance treatment processes (e.g. granular or powdered activated carbon beds, ultraviolet/titanium dioxide oxidation processes), however, these are expensive to operate on a commercial scale. ${ }^{9,12}$

In order to protect river catchments a number of initiatives have been proposed rather than 'end of pipe' solutions. The industry-led Metaldehyde Stewardship Group (MSG), based in the UK, began a campaign called 'Get Pelletwise' (http://www.getpelletwise.co.uk/). This educational initiative was directed at large-scale users of slug pellets and aimed to try and prevent or minimise the movement of metaldehyde to water sources. The campaign developed best practice guidelines when using metaldehyde, covering issues including dosage rates per hectare, maximum pellet application rates, no application within $10 \mathrm{~m}$ of a watercourse, no application when heavy rain or winds were forecast and no application if there was flow in field drains. ${ }^{13}$ Several water companies, rivers trusts and non-governmental agencies in the UK have also introduced other projects such as the Anglian Water 'Slug It Out' campaign (http://www.anglianwater.co.uk/slugitout) aimed at protecting a number of reservoirs. Many water companies in the UK (e.g. Affinity Water Ltd., Severn Trent Water plc, Southern Water, Thames Water and United Utilities plc) have on-going catchment-based initiatives, including payments for non-usage, designed to reduce direct inputs of metaldehyde. These initiatives also include the substitution of metaldehyde by alternative molluscicides such as ferric phosphate $\left(\mathrm{FePO}_{4}\right){ }^{14}$

Metaldehyde is monitored in surface waters typically using weekly or monthly spot (bottle or grab) samples of water (0.25-1 L) followed by gas or liquid chromatography with mass spectrometric detection. Often the effectiveness of this monitoring approach is challenging, particularly where 
concentrations fluctuate over short-time intervals (e.g. hours to days), such as those events associated with the sporadic application of pesticides. One approach to improve temporal resolution is to increase the frequency of spot water sampling or the use of other monitoring methods such as timetriggered automated samplers (e.g. ISCO - http://www.teledyneisco.com) or on-line analytical systems. However, this equipment requires high capital input, requires regular maintenance and can be subject to damage or theft in the field. ${ }^{15} \mathrm{An}$ alternative is the use of passive sampling devices that can overcome many of these drawbacks; as they are relatively low-cost, non-mechanical, require no external power and are easily deployable in many field conditions.

A wide range of passive sampling devices is available to monitor different types of organic pollutants found in the aquatic environment. ${ }^{16}$ These include semi-permeable membranes devices, polymer sheets (e.g. low-density polyethylene or silicone rubber) or Chemcatcher ${ }^{\circ}$ for non-polar pollutants ${ }^{17}$ and the polar organic chemical integrative sampler (POCIS), ${ }^{18,19}{ }^{0-D G T^{20-22}}$ and the polar version of the Chemcatcher ${ }^{\circ}$ for polar pollutants. ${ }^{23}$ Samplers comprise typically a receiving phase selective for the compounds of interest, which is usually overlaid by a thin diffusion-limiting barrier or membrane. Both components are often contained in an inert metal or plastic housing. Devices can be deployed in the field for extended periods (e.g. 1-4 weeks) where analytes are continually sequestered. Depending on the deployment regime, samplers can yield the equilibrium or the timeweighted average (TWA) concentration of a pollutant. ${ }^{24}$ Recently a new variant of the Chemcatcher ${ }^{\circ}$ passive sampler for monitoring metaldehyde in surface water has been described..$^{25}$ This comprised a hydrophilic-lipophilic-balanced Horizon Atlantic ${ }^{\mathrm{TM}}$ HLB-L disk as the receiving phase overlaid with a polyethersulphone (PES) membrane.

We describe the use of the Chemcatcher for monitoring metaldehyde at two riverine catchments in the UK (River Dee and River Thames) over a twelve-month period. The performance of the device was evaluated alongside spot water sampling (typically every 7-14 days) undertaken as part of routine water quality monitoring programmes. By undertaking a yearlong investigation, we were able to encompass the agricultural application period of metaldehyde (between August-December) at both locations. This study enabled a better understanding of the stochastic inputs of metaldehyde linked to rainfall events and application periods together with the related spatiotemporal fluctuations within two river catchments. These trials represent some of the largest and longest evaluations of the performance of passive sampling devices in a river catchment to be reported. The work highlights the applicability of using passive samplers within the operational constraints of routine monitoring programmes that are undertaken to fulfil various regulatory requirements. Data obtained from the use of the Chemcatcher ${ }^{\circ}$ in these field trials has potential in the future to be incorporated into river catchment management programmes and to provide improved cost-effective information for the future development of environmental remediation strategies.

\section{Experimental}

\section{River Dee catchment and sampling locations}

The River Dee catchment is situated in North Wales and North Western England flowing from the highlands of Snowdonia, through the lowlands of Chester and out into the Irish Sea. It is a vitally important natural water resource for communities in this region, supporting a rich environment for wildlife. The upland tributaries of the Dee tend to be 'flashy' in nature with an average annual rainfall of $\sim 2,000 \mathrm{~mm}$, compared with $\sim 700 \mathrm{~mm}$ in the lowlands (http://www.welshdeetrust.com/). The lowland reaches tend to have slower flow rates and a greater groundwater contribution than the upper catchment. Raw water is abstracted from a number of sites across the catchment and is treated to provide drinking water to a population of almost three million. Water extraction for this purpose is managed under the Dee Regulation Scheme. In 1999, the River Dee became the UK's first designated Water Protection Zone. Since its introduction there has been a marked reduction in industrial pollution, however, in recent years the amount of agricultural pesticides detected in the river has risen (http://www.welshdeetrust.com/). As a consequence, regional water companies and national governmental environmental regulators monitor pesticides routinely. 
Pollution in the River Dee catchment is being investigated by a number of neighbouring water companies, environment agencies and non-government organisations. United Utilities plc are specifically looking at inputs of both metaldehyde and a range of acidic herbicides across the entire Dee Catchment upstream from the water intake at Chester. This study investigated metaldehyde in the lower eastern part of the catchment. Here the land use is largely improved grassland $\left(822 \mathrm{~km}^{2}\right)$ with substantial areas of winter wheat $\left(60 \mathrm{~km}^{2}\right)$, maize $\left(55 \mathrm{~km}^{2}\right)$ and winter barley $\left(24 \mathrm{~km}^{2}\right)$ together with smaller fragmented coverage of oil seed rape. These farming activities require the extensive use of metaldehyde at specific times of the year to control mollusc infestations. Seven high-risk sites (Aldford Brook, D1; Coddington, D3; Emral Brook, D4; Golborne, D5; Pulford Brook, D6; Shell Brook, D7 and Worthenbury Brook, D8) and one low risk site (Ceiriog, D2) were selected for inclusion in this study. Fig. 1 shows the inter-connectivity of the various brooks and rivers within the catchment that flow in to the River Dee towards Chester.

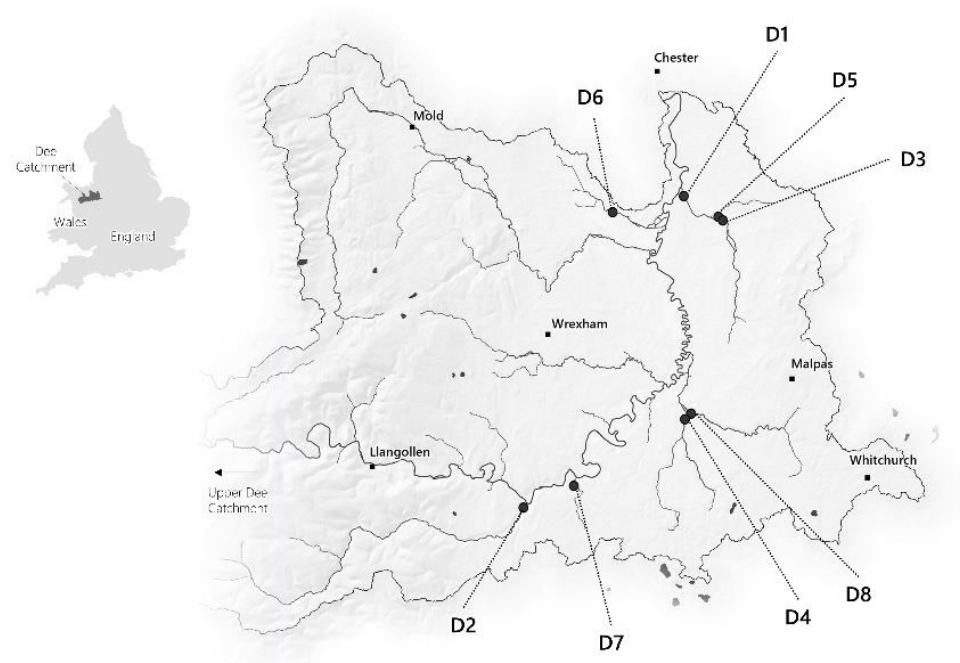

Fig. 1 Map of sampling site locations in the lower eastern part of the River Dee catchment. Key to the location of sampling sites: Aldford Brook (D1), Ceiriog (D2), Coddington (D3), Emral Brook (D4), Golborne (D5), Pulford Brook (D6), Shell Brook (D7) and Worthenbury Brook (D8). A version of this map giving details of land use is shown as Fig. $\mathrm{S1}$ in electronic supplementary information.

At five locations (D1, D3, D5 and D6) farmers were subsidised to use ferric phosphate-based slug pellets as part of United Utilities' Sustainable Catchment Management Programme (SCaMP). ${ }^{26}$ This initiative has been in operation since 2015 . This programme aims to protect and improve water quality in the region and hence to reduce drinking water treatment costs. The field trial described in this paper was undertaken between $13^{\text {th }}$ January 2016 to $25^{\text {th }}$ January 2017.

\section{River Thames catchment and sampling locations}

The River Thames is the longest river in England $(255 \mathrm{~km})$ with the catchment covering $~ 10,000 \mathrm{~km}^{2}$ in Southern England. The river supplies drinking water to approximately 14 million people. Precipitation in the catchment ranges from $600-900 \mathrm{~mm} \mathrm{y}^{-1}$. The main land use type is arable agriculture, which covers about $57 \%$ of the whole catchment. The average water concentration of metaldehyde between 2011 and 2015 was above the PCV at 31 out of 140 sites across the Thames catchment. ${ }^{27}$ For this field trial six sites within the greater River Thames catchment were selected for investigation (Fig. 2). These were identified as 'at risk' sites by Affinity Water Ltd. and Thames Water within their on-going 'risk-based' monitoring programmes. Three sites were in the borough of Epping 
Forest on Cobbins Brook (Swimming Pool (T1); Galley Hill (T2); Cobbins End (T3)). These locations were predominantly non-irrigated arable land (62\%) and pastures (18\%). Surface water bodies accounted for $0.65 \%$ of coverage. ${ }^{28}$ Higher concentrations were expected in the surface water at these sites due to run-off from the surrounding arable farmland. Two sites were situated within Tillingbourne (River Wey (T4)) and Weybridge (Lower Wey (T5)). Here arable land coverage was much lower (4-16\%) with some surface water bodies present $(2-7 \%){ }^{28}$ Hence, lower concentrations of metaldehyde were expected to enter surface water bodies in this region. The final site was located on the River Enborne in West Berkshire (Shalford Bridge (T6)). In this area arable land coverage was $50 \%$ and surface water bodies $0.5 \%{ }^{28}$ The trial was undertaken between $20^{\text {th }}$ July 2016 to $20^{\text {th }}$ July 2017.

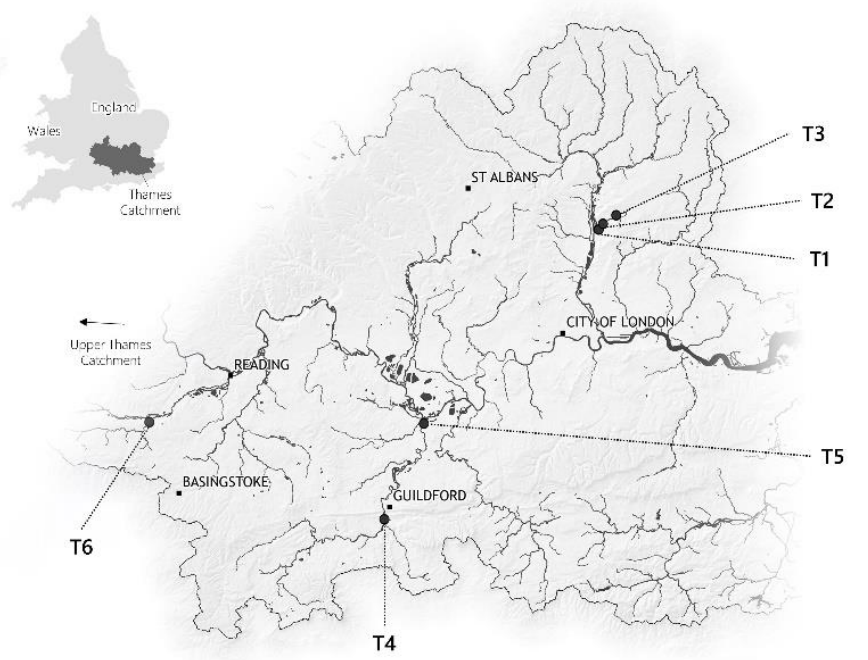

Fig. 2 Map of sampling site locations within the greater River Thames basin. Key to the location of sampling sites: Cobbins Brook (Swimming Pool (T1)); Galley Hill (T2); Cobbins End (T3); Tillingbourne (River Wey (T4)); Weybridge (Lower Wey (T5)) and the River Enborne in West Berkshire (Shalford Bridge (T6)). A version of this map giving details of land use is shown as Fig. S2 in electronic supplementary information.

\section{Spot water sampling and analysis}

For the River Dee field trial, spot samples of river water were collected every 14 days (corresponding to the deployment period of the Chemcatcher ${ }^{\circ}$ ) over the twelve-month period. Water samples (250 $\mathrm{mL}$ ) were collected into pre-cleaned, screw-topped polyethylene terephthalate bottles and stored without preservative at $\sim 4{ }^{\circ} \mathrm{C}$ until analysis (within seven days of collection). Metaldehyde was quantified in the spot water samples by liquid chromatography tandem mass spectrometry (LCMS/MS) using an Agilent 1200RR LC system coupled to an Agilent 6460 tandem mass spectrometer (Agilent Technologies, Santa Clara, USA). The instrument was interfaced with an on-line solid-phase extraction system fitted with a Waters Oasis ${ }^{\circ}$ HLB cartridge. The limit of quantification (LoQ) of the method was $10 \mathrm{ng} \mathrm{L}^{-1}$, calculated as three times the limit of detection (LoD). The full analytical procedure has been described previously by Schumacher et al. ${ }^{29}$

For the River Thames field trial, regular spot samples of river water were collected by Thames Water and Affinity Water Ltd. as part of their routine water quality monitoring programme. Over the twelve-month period the frequency of collection varied, but was typically between 7 and 14 days. The Thames Water spot samples were collected into $250 \mathrm{~mL}$ plastic bottles and stored at $\sim 4{ }^{\circ} \mathrm{C}$ until analysis (within seven days of collection). Our experiments showed that metaldehyde was stable under these storage conditions and there were no measurable losses of analyte over this time period. 
The Affinity Water spot samples were collected into $40 \mathrm{~mL}$ amber screw top glass bottles with $0.36 \%$ $\mathrm{w} / \mathrm{v}$ sodium thiosulphate solution $(0.25 \mathrm{~mL}$ ) added as a preservative (Affinity Water Ltd.). Samples were stored at $\sim 4{ }^{\circ} \mathrm{C}$ until analysis (within two weeks of collection).

Both laboratories are nationally accredited (United Kingdom Accreditation Service, UKAS) and used a routine and validated electrospray ionisation LC-MS/MS (Agilent 6490) method (ISO/IEC 17025:2005) for the quantification of metaldehyde in the water samples. Samples were analysed by an on-line solid-phase extraction system interfaced to the liquid chromatograph. The mobile phase was a $0.1 \%$ acetic acid:acetonitrile gradient. Before analysis water samples were spiked with deuterated metaldehyde- $\mathrm{d}_{16}$ (> 99 atom \% deuterium) as an internal standard and sodium thiosulphate. Samples were analysed using multiple reaction monitoring MS/MS, with the sodium adduct ion formed with metaldehyde monitored by the first quadrupole. The LoQ of the method was $9 \mathrm{ng} \mathrm{L}^{-1}$, calculated as three times the LoD.

\section{Chemcatcher ${ }^{\circledR}$ passive samplers}

Preparation. Three component PTFE Chemcatcher ${ }^{\circ}$ bodies (Atlantic design) were obtained from A T Engineering (Tadley, UK). Components were cleaned by soaking overnight in a 5\% Decon 90 (Decon Laboratories Ltd., Hove, UK) solution and rinsed with water. This was followed by washing in acetone (ultrasonic bath for $10 \mathrm{~min}$ ), removal, rinsed with water and dried. A Horizon Atlantic ${ }^{\mathrm{TM}}$ hydrophiliclipophilic balanced (HLB-L) disk (47 mm diameter) (Labmedics Ltd, UK) used as the receiving phase and was cleaned by soaking in methanol overnight. The disk was activated by passing HPLC grade methanol $(50 \mathrm{~mL})$ followed by HPLC grade water $(100 \mathrm{~mL})$ through the disk under gentle vacuum. Disks were then left submerged in Milli-Q water until assembly to prevent them from drying out. Polyethersulfone (PES) (Supor 200, $0.2 \mu \mathrm{m}$ pore diameter; cut to $52 \mathrm{~mm}$ diameter disks) (Pall Europe Ltd., Portsmouth, UK) was used as the diffusion limiting membrane. Membranes were cleaned by soaking in methanol overnight to remove any artefacts from the manufacturing process then rinsed with water, and kept wet until use. Samplers were assembled by placing a HLB-L receiving phase disk rough side down onto the Chemcatcher supporting plate followed by a preconditioned PES membrane ensuring no air bubbles were present between the two surfaces. The disk and membrane were then secured using the Chemcatcher ${ }^{\circ}$ retaining ring. Assembled devices were kept submerged in Milli-Q water until use. Prior to taking the samplers to the field, the PTFE lid was fitted ensuring that there is a small quantity of water remaining in the top well and then secured.

Deployment and retrieval. Chemcatcher samplers were deployed at the River Dee (triplicate devices) and River Thames (duplicate devices) for consecutive periods of 2 weeks. During each deployment and retrieval procedure a field blank device was exposed and then resealed and handled subsequently as for the field exposed samplers. Previous work had shown that the Chemcatcher maintained linear (time integrative) uptake for over 14-days for metaldehyde enabling TWA concentrations to be calculated. ${ }^{25}$ Restricting the exposures to 14-days also helped to minimise any biofouling of the PES membrane, which may occur with prolonged deployments. To ensure that the samplers remained submerged throughout the deployment, they were placed in bespoke deployment rigs. At the River Dee, Chemcatcher samplers were housed inside stainless steel cages and placed on the river bed (Fig. S3). Due to security and theft implications at the River Thames sites, a robust plastic sheet deployment rig was used, with the samplers maintained $\sim 0.5 \mathrm{~m}$ below the water surface (Fig. S4). Both systems were held in the river using a weight. Upon retrieval Chemcatcher samplers were resealed using the PTFE lid, labelled and then wrapped in aluminium foil. Devices were placed in a cool box, transported to the laboratory, where they were stored at $\sim 4^{\circ} \mathrm{C}$ until analysis.

Extraction and analysis. In the laboratory the Chemcatcher ${ }^{\circ}$ samplers were dissembled, the receiving phase disks removed and placed into pre-cleaned aluminium foil pouches and stored at $\sim 4^{\circ} \mathrm{C}$. The PES membranes were discarded. Prior to extraction, HLB-L disks were allowed to dry on solvent rinsed aluminium foil ( $48 \mathrm{~h}$ at room temperature). Metaldehyde was then eluted from the disks (methanol, 
$40 \mathrm{~mL}$ ) under gravity using a glass extraction funnel manifold, with the eluent collected into precleaned glass vials $(60 \mathrm{~mL})$. Water $(1 \mathrm{~mL})$ was added to the vial (to act as a keeper to prevent any loss of metaldehyde) and the solution evaporated (Genevac 'Rocket' centrifugal rotary evaporator, Genevac Ltd., Ipswich, UK) to $\sim 0.5 \mathrm{~mL}$. The extract was transferred to a pre-cleaned vial $(2 \mathrm{~mL})$ and the solution adjusted to $1 \mathrm{~mL}$ with methanol. Metaldehyde in extracts obtained from Chemcatcher ${ }^{\circ}$ samplers was analysed using a similar procedure as for the spot water samples with the following modification. One hundred $\mu \mathrm{L}$ of extract was added to a silanised glass auto-sampler vial containing water $\left(900 \mu \mathrm{L}\right.$ ) and $20 \mu \mathrm{L}$ of internal standard solution (metaldehyde- $\mathrm{d}_{16}, 50 \mu \mathrm{g} \mathrm{\textrm {L } ^ { - 1 }}$ ) and then analysed as above. The LoQ of the method was $0.45 \mathrm{ng} \mathrm{L}^{-1}$, calculated as three times the LoD. This value is approximately 20 lower than that attained by the analytical method used for the analysis of the spot water samples. Over a typical deployment period of 14 days the Chemcatcher ${ }^{\circledR}$ effectively sampled $224 \mathrm{~mL}$ of water and hence this accounted for the lower LoQ.

\section{Theory of passive sampling}

The theory of the uptake of a chemical by a passive sampling device is well known and has been described extensively elsewhere. ${ }^{16,24,30}$ The uptake of an analyte over the time integrative (linear) period is as shown in eqn (1).

$$
C w=\frac{M_{S(t)}-M_{0}}{R_{S} \times t}
$$

Where: $C_{w}=$ concentration $\left(\mathrm{ng} \mathrm{L}^{-1}\right)$ of analyte in water

$M_{s(t)}=$ mass $(\mathrm{ng})$ of analyte in Chemcatcher receiving phase disk after exposure time $t$ (day)

$M_{0}=$ mass ( $\mathrm{ng}$ ) of analyte in receiving phase disk of Chemcatcher field blank

$R_{S}=$ sampler uptake rate of analyte $\left(\mathrm{Lday}^{-1}\right)$

For laboratory and 'in-field' calibration studies, $R_{s}$ can be calculated from eqn (1) using the slope $\left(M_{s(t)}\right.$ $t^{-1}$ ) of the regression of the mass in the sampler upon time (over the linear portion of the uptake data) and the concentration $\left(C_{w}\right)$ in the water. Values for $R_{s}$ can then be used in field trials to estimate $C_{w}$ and this corresponds to the TWA concentration of the chemical over the deployment period. Time weighted average (TWA) concentrations of metaldehyde were calculated using eqn 1 . The uptake rate $\left(R_{s}\right)$ was determined previously in a laboratory calibration study as $16 \mathrm{~mL}$ day ${ }^{-1} .{ }^{25}$ This $R_{s}$ value was measured at a water temperature of $\left(5.0 \pm 1.0^{\circ} \mathrm{C}\right)$ and a water velocity of $\sim 0.2 \mathrm{~m} \mathrm{~s}^{-1}$ over the face of the sampler bodies. These conditions are typical of the temperature and flow of rivers in the UK during late autumn to winter when metaldehyde is most prevalent in catchments.

\section{Results and discussion}

\section{River Dee catchment}

Spatiotemporal variation of metaldehyde based on spot sampling. The concentration of metaldehyde found in spot samples of water from the eight locations (Fig. 1 and Fig. S1) within the lower eastern part of the catchment is shown in Fig. 3 (site D4) and in Figs. S5-S11 (sites D1-D3 and D5-D8). These sites were selected, as metaldehyde was known to be used agriculturally in these catchments. In this part of the catchment there are significant areas of autumn sown brassicas, oil seed rape and winter wheat, hence there are wide spread agricultural use of molluscicides. It was expected farmers in these areas abide the MSG 'Get Pelletwise' guidelines. The maximum application rate stated in these guidelines is $210 \mathrm{~g}$ metaldehyde per hectare. The time period of the trial coincided with the permitted application period of metaldehyde in the UK (between 1st August-31st December). During the study there were many instances when the concentration of metaldehyde in the spot water samples was below the LoQ of the analytical method used. At the eight locations the percentage of samples that were found to be below the LoQ varied between $48-96 \%$ (Table 2). Throughout the study, at all locations there was little variability in the concentrations of metaldehyde measured in the spot samples of water. Apart from one occasion (Emral Brook (D4) 30 $0^{\text {th }}$ November 2016 - see Fig. 3) 
concentrations were below the permitted PCV $\left(100 \mathrm{ng} \mathrm{L}^{-1}\right)$ for drinking water. There was evidence that the concentration of metaldehyde in the surface water increased after high rainfall events during early June $(28 \mathrm{~mm}$ on $09 / 06 / 16)$ and mid-November ( $26 \mathrm{~mm}$ on $21 / 11 / 16)$. The elevated concentration observed in June was likely to be as a result of wash-out of residual metaldehyde from the soil or possibly from horticultural use of molluscicides in the growing period for summer plants. The higher concentrations seen in November are related to the increased application of metaldehyde for agricultural purposes.

Table 2. Number of spot samples of water collected at either River Dee catchment or River Thames catchment and those above or below the limit of quantification (LoQ) of the analytical method used

\begin{tabular}{|c|c|c|c|c|c|}
\hline Site name & $\begin{array}{l}\text { Site } \\
\text { code }\end{array}$ & $\begin{array}{c}\text { Number of } \\
\text { spot samples } \\
\text { water } \\
\text { collected }\end{array}$ & $\begin{array}{c}\text { Number of } \\
\text { spot samples } \\
\text { of water } \\
\text { above LoQ }\end{array}$ & $\begin{array}{c}\text { Number of } \\
\text { spot samples } \\
\text { of water below } \\
\text { LoQ }\end{array}$ & $\begin{array}{l}\text { Percentage } \\
\text { below LoQ }\end{array}$ \\
\hline \\
\hline Aldford Brook & D1 & 26 & 11 & 15 & 58 \\
\hline Ceiriog & D2 & 27 & 1 & 26 & 96 \\
\hline Coddington & D3 & 27 & 6 & 21 & 78 \\
\hline Emral Brook & D4 & 27 & 3 & 24 & 89 \\
\hline Golborne & D5 & 27 & 14 & 13 & 48 \\
\hline Pulford Brook & D6 & 27 & 10 & 17 & 63 \\
\hline Shell Brook & D7 & 27 & 4 & 23 & 85 \\
\hline Worthenbury Brook & D8 & 26 & 9 & 17 & 65 \\
\hline \multicolumn{6}{|l|}{$\begin{array}{l}\text { River Thames } \\
\text { catchment }\end{array}$} \\
\hline $\begin{array}{l}\text { Cobbins Brook } \\
\text { (swimming pool) }\end{array}$ & $\mathrm{T} 1$ & 35 & 33 & 2 & 6 \\
\hline $\begin{array}{l}\text { Cobbins Brook } \\
\text { (Galley hill) }\end{array}$ & $\mathrm{T} 2$ & 35 & 33 & 2 & 6 \\
\hline $\begin{array}{l}\text { Cobbins Brook } \\
\text { (Cobbins end) }\end{array}$ & $\mathrm{T} 3$ & 35 & 33 & 2 & 6 \\
\hline $\begin{array}{l}\text { River Wey } \\
\text { (Tillingbourne) }\end{array}$ & T4 & 29 & 9 & 20 & 69 \\
\hline $\begin{array}{l}\text { Lower Wey } \\
\text { (Weybridge) }\end{array}$ & T5 & 29 & 9 & 20 & 69 \\
\hline $\begin{array}{l}\text { River Enbourne } \\
\text { (Shalford bridge) }\end{array}$ & T6 & 54 & 32 & 22 & 41 \\
\hline
\end{tabular}

However, it is difficult to link concentrations of metaldehyde found in the River Dee directly to rainfall events during the study as there is a number of additional influential factors within the catchment that need to be taken into consideration. ${ }^{9}$ These include method and application rates of metaldehyde, croppage, field slope and drainage, soil type and moisture deficit. The significance of each of these factors on the concentration of metaldehyde found within such a complex river catchment is impossible to predict with certainty. The low inputs of metaldehyde found at sites D1, D3, D5 and D6 are likely to be of a result of farmers switching their molluscicide to ferric phosphatebased slug pellets as part of United Utilities' Sustainable Catchment Management Programme (SCaMP). ${ }^{26}$ The very low concentration of metaldehyde (detected in only one spot sample at $15 \mathrm{ng} \mathrm{\textrm {L } ^ { - }}$ $\left.{ }^{1}\right)$ found at site D2 is related to land type. Here the area is dominated by acidic, wet and peaty land that is not of a suitable quality for growing crops. 


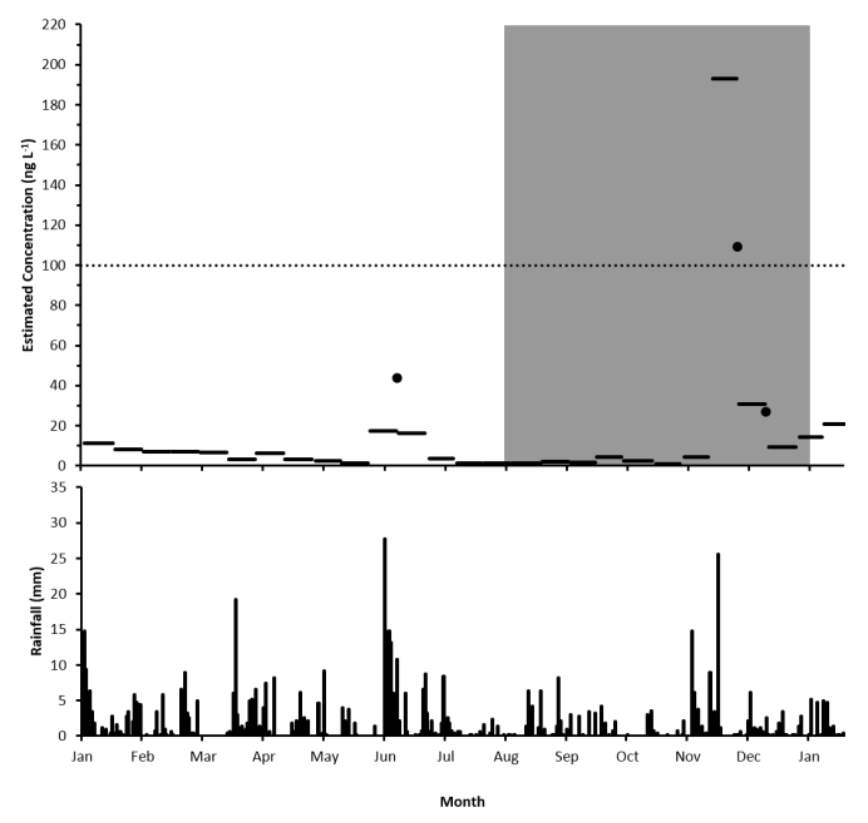

Fig. 3 Concentration of metaldehyde ( $\left.n g \mathrm{~L}^{-1}\right)$ found in spot samples of water ( $\bullet$ ) and time weighted average (TWA) concentrations found with the Chemcatcher passive sampler (-) estimated using Equation 1 at Emral Brook (D4) during the River Dee catchment field trial (January 2016-Janaury 2017). Daily rainfall $(\mathrm{mm})$ in the area over the same period is also shown (data courtesy of Natural Resources Wales information data base ${ }^{\odot}$ - all rights reserved). The line (…....) shows the European Union's Drinking Water Directive limit of $100 \mathrm{ng} \mathrm{L}^{-1}$ for a single pesticide. The grey shaded box indicates the time period in the UK when metaldehyde is applied agriculturally to land. The limit of quantification for spot samples of water was $10 \mathrm{ng} \mathrm{L}^{-1}$ and for extracts obtained from the Chemcatcher passive sampler was $0.45 \mathrm{ng} \mathrm{L}^{-1}$. Only data points above these limits of quantification are shown in the figure.

Comparison of Chemcatcher and spot sampling data for metaldehyde. The amount of metaldehyde found in all the field blank samplers was below the LoQ $\left(<0.45 \mathrm{ng} \mathrm{L}^{-1}\right)$. For all samplers deployed throughout the trial there was minimal biofouling of the PES membrane. Due to its high polarity (log $K_{\text {ow }}=0.12$ ) it was expected that metaldehyde will be freely dissolved in the water column, with limited binding to any particulate or dissolved organic matter present. Previous work in our laboratory had shown that there was no measurable lag phase in the uptake of metaldehyde by the Chemcatcher ${ }^{\circ} .{ }^{25}$ TWA concentrations of metaldehyde were calculated using Eqn 1 . The mean values obtained from the triplicate deployments are shown in Fig. 3 (site D4) and in Figs. S5-S11 (sites D1-D3 and D5-D8). Sampler deployments were restricted to 14 days as inputs of metaldehyde into river catchments are known to be episodic. ${ }^{9,27}$ Restricting deployments to this time period also minimised any likelihood of biofouling on the surface of the PES membrane.

It was estimated (using Eqn 1 and the $R_{s}$ value) that even for short periods of time (e.g. pollutant present for 1 day out of a total deployment period of 14 days at a concentration of metaldehyde of only $6 \mathrm{ng} \mathrm{L}^{-1}$ ) sufficient sequestration of metaldehyde would be obtained on the receiving phase disk ( $0.1 \mathrm{ng}$ ) for quantitative analysis.

At all sites the TWA concentrations of metaldehyde followed a similar pattern to the concentrations found using the spot water sampling approach. It needs to be recognised in the interpretation of the two sets of data, that the LoQ for the analysis of the extracts obtained from the 
Chemcatcher is $\sim 20$ times lower than that obtainable by the analysis of spot samples of water. Hence, unlike with the spot samples of water (see Table 2), metaldehyde could be detected in all the extracts obtained from the Chemcatcher ${ }^{\circ}$. This, therefore, represents a significant advantage of using passive sampling methods in river catchment investigations. As with the spot samples, higher TWA values were found during the agricultural application period for metaldehyde and during elevated rainfall periods. It is difficult to compare directly the water quality data obtained using the two monitoring techniques, particularly where the concentration of pollutant is episodic. ${ }^{31-33}$ Firstly, there is no information on how the concentration of metaldehyde varied in the time interval between collections (typically every 14 days) of spot samples of water. This is particularly important for pollutants such as metaldehyde, where infrequent spot sampling can easily miss sporadic inputs. Secondly, there is evidence from other field trials that polar passive samplers are unable to fully integrate stochastic events where there are rapidly changing concentrations of pollutants as could be occurring in the River Dee. ${ }^{34,35}$

For metaldehyde, its relatively low $R_{s}$ value $\left(16 \mathrm{~mL} \mathrm{day}^{-1}\right)$ may lead to an under-sampling (poor integration) of a rapidly (e.g. a few hours) occurring pollution event. The inverse, however, appears to have occurred at one occasion (corresponding to the highest rainfall) during the prolonged pollution events within the agricultural application period. Here, at all sites apart from Ceiriog (D2) the TWA concentrations obtained from the Chemcatcher ${ }^{\circ}$ were overestimates compared to the spot water sample concentrations for the same period. One possible reason is that the $R_{s}$ value increased due to the more turbulent conditions as a consequence of higher water flow rates in the catchment. This would lead to an increased sequestration of metaldehyde and hence a higher TWA concentration being calculated (Eqn 1). In the laboratory $R_{s}$ was measured as $16 \mathrm{~mL}^{\text {day }}{ }^{-1}$ (water temperature $=5.0$ $\pm 1.0{ }^{\circ} \mathrm{C}$ and water velocity $~ 0.2 \mathrm{~m} \mathrm{~s}^{-1}$ ). For example at Emral Brook (D4) on $30^{\text {th }}$ November, the concentration of metaldehyde in the spot sample of water was $110 \mathrm{ng} \mathrm{L}^{-1}$ (see Fig. 3). The mass of metaldehyde sequestered on the HLB-L receiving phase for the Chemcatcher ${ }^{\circ}$ deployed between $17^{\text {th }}$ $30^{\text {th }}$ November 2016 was $40 \mathrm{ng}$. Using these values in Eqn 1 this resulted in an $R_{s}=28 \mathrm{~mL} \mathrm{day}^{-1}$, approaching twice the value measured in the laboratory study. ${ }^{25}$ This deployment period coincided with high rainfall (peak value $=26 \mathrm{~mm}$ ) in the catchment that would have led to high water flows in the Brook. These findings indicate that the $R_{s}$ value is sensitive to water velocity. It is also expected that in periods of low water flow, the inverse would apply and $R_{s}$ would decrease.

One solution to overcome this difficulty of the $R_{s}$ varying with changing environmental conditions during field deployments is the use of performance reference compounds (PRCs). PRCs have been shown to be effective with samplers used for the sequestration of non-polar pollutants. ${ }^{36,37}$ The effectiveness of this concept for use with polar passive samplers is not fully proven and alternative solutions such as the use of passive flow monitors (e.g. rate of dissolution of calcium sulphate casts) and increasing membrane resistance have been suggested and warrant further study with the Chemcatcher $^{\circ} .38,39$

\section{River Thames catchment}

Spatiotemporal variation of metaldehyde based on spot sampling. The concentration of metaldehyde found in spot samples of water from the six locations (Fig. 2 and Fig. S2) within the greater River Thames catchment is shown in Figs. 4 and 5 (sites T1 and T6 respectively) and in Figs. S12-S15 (sites T2-T5). These locations were selected for investigation as metaldehyde had been found previously during monitoring activities undertaken by Affinity Water Ltd. and Thames Water and were considered 'at risk' sites. As was found in the other field study, there were several instances where metaldehyde could not be detected in the spot samples of water. In the greater River Thames catchment this varied between 6-69\% (Table 2). Metaldehyde was most frequently detected in the three Cobbins Brook sites. 

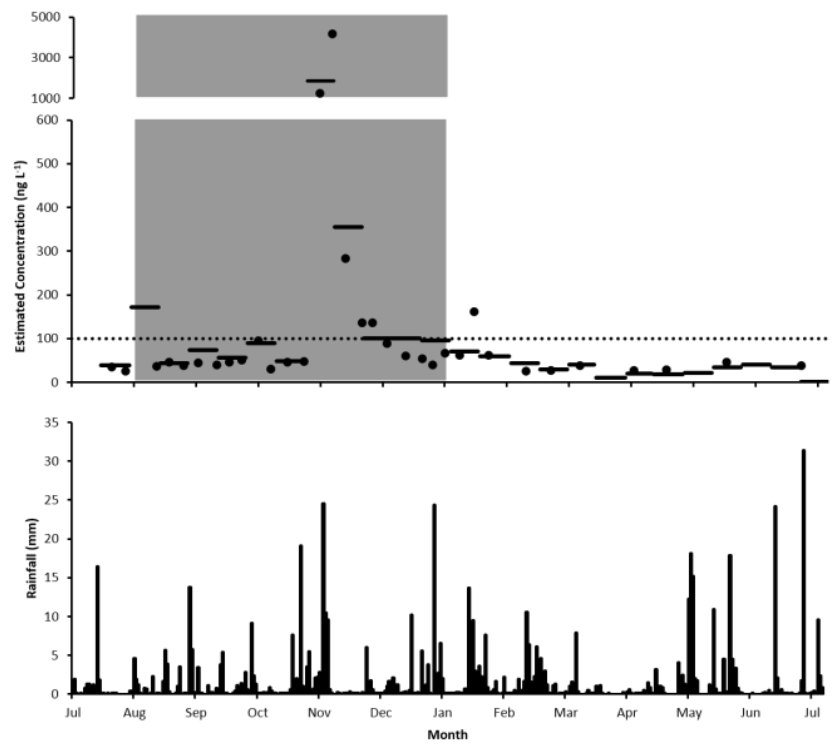

Fig. 4 Concentration of metaldehyde ( $\left.n g L^{-1}\right)$ found in spot samples of water ( $\bullet$ ) and time weighted average (TWA) concentrations found with the Chemcatcher passive sampler (-) estimated using Equation 1 at Cobbins Brook (Swimming Pool (T1)) during the greater River Thames field trial (July 2016-July 2017). Daily rainfall $(\mathrm{mm})$ in the South East England area (HadUKP http://www.metoffice.gov.uk/hadobs/hadukp/) is also shown. The line (…...) shows the European Union's Drinking Water Directive limit of $100 \mathrm{ng} \mathrm{L}^{-1}$ for a single pesticide. The grey shaded boxes indicates the time period in the UK when metaldehyde is applied agriculturally to land. The limit of quantification for spot samples of water was $9 \mathrm{ng} \mathrm{L}^{-1}$ and for extracts obtained from the Chemcatcher passive sampler was $0.45 \mathrm{ng} \mathrm{L}^{-1}$. Only data points above these limits of quantification are shown in the figure.

The trial captured the permitted agricultural application period of metaldehyde. At the three sites at Cobbins Brook (T1-T3) there were elevated concentrations of metaldehyde (up to 4,180 ng L-1 ). There were several exceedances of the permitted PCV ( 12-42 times higher) during the period $1^{\text {st }}$ August to $31^{\text {st }}$ December 2016. As metaldehyde is difficult to remove in drinking water treatment works this could be problematic if such waters were abstracted for the production of potable supplies. These exceedances occurred when there was increased rainfall in the catchment. Higher concentrations were not unexpected as this area contains extensive horticultural and arable farmland that drains directly into the Brook. Previous work in the River Thames catchment has shown that the rate of application of slug pellets is the key factor of increased concentrations of metaldehyde in surface waters. ${ }^{27}$ At the other three sites (T4-T6) the concentration of metaldehyde was lower, with just one exceedance of the PCV (130 $\mathrm{ng} \mathrm{L}^{-1}$ on the $22^{\text {nd }}$ November 2016 at T6). The use of molluscicides at these locations is lower to due to the type of land coverage (a mixture of arable, grassland and built up areas with gardens). 


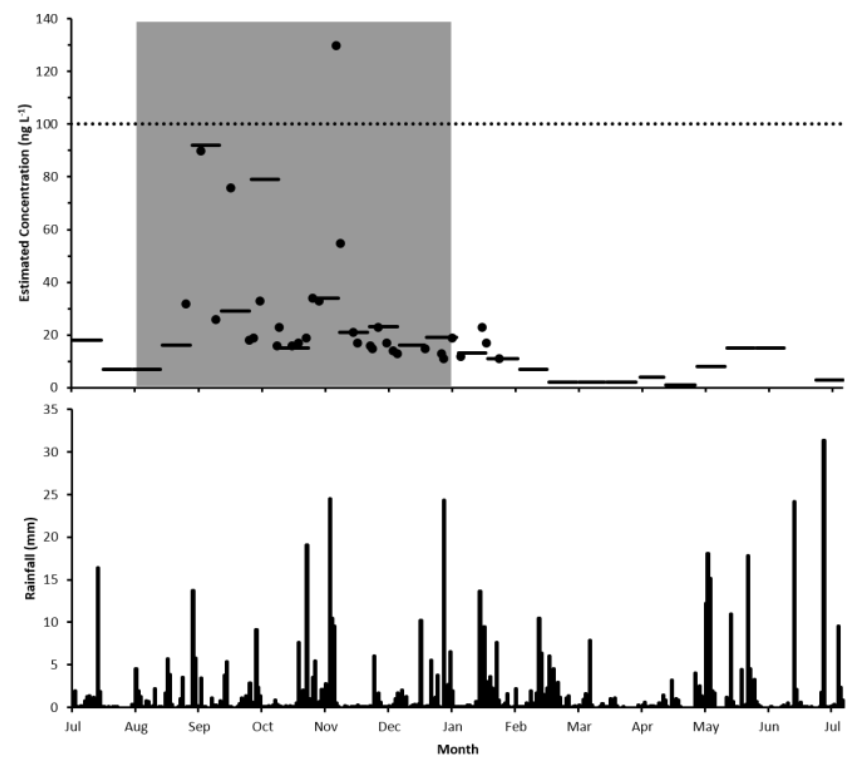

Fig. 5 Concentration of metaldehyde ( $\left.n g L^{-1}\right)$ found in spot samples of water ( $\bullet$ ) and time weighted average (TWA) concentrations found with the Chemcatcher passive sampler (-) estimated using Equation 1 at River Enborne in West Berkshire (Shalford Bridge (T6)) during the greater River Thames field trial (July 2016-July 2017). Daily rainfall $(\mathrm{mm})$ in the South East England area (HadUKP http://www.metoffice.gov.uk/hadobs/hadukp/) is also shown. The line (.......) shows the European Union's Drinking Water Directive limit of $100 \mathrm{ng} \mathrm{L}^{-1}$ for a single pesticide. The grey shaded box indicates the time period in the UK when metaldehyde is applied agriculturally to land. The limit of quantification for spot samples of water was $9 \mathrm{ng} \mathrm{L}^{-1}$ and for extracts obtained from the Chemcatcher passive sampler was $0.45 \mathrm{ng} \mathrm{L}^{-1}$. Only data points above these limits of quantification are shown in the figure.

Comparison of Chemcatcher ${ }^{\oplus}$ and spot sampling data for metaldehyde. As with the River Dee trial, the amount of metaldehyde found in all the field blank samplers was below the LoQ $\left(<0.45 \mathrm{ng} \mathrm{L}^{-1}\right)$ and there was minimal biofouling of the PES membrane. TWA concentrations of metaldehyde were calculated using Eqn 1, and the mean values obtained from the duplicate deployments are shown in Figs. 4 and 5 (sites T1 and T6 respectively) and in Figs. S12-S15 (sites T2-T5). With the exception of one sample (collected at River Enborne, Shalford Bridge (siteT6)), metaldehyde could be detected in all extracts obtained from the investigation, again showing one of the benefits of using the passive sampling approach. For all sites there was generally good agreement between the two monitoring techniques, with elevated TWA concentrations being measured during the metaldehyde application period. As with the above trial, there is no information on the changes in concentration of metaldehyde between the 14-day spot sample collections. The variation of $R_{s}$ with water velocity appears to have a lesser impact than that observed in the River Dee trial.

\section{Potential use of passive samplers in routine regulatory monitoring programmes}

Understanding the sources, fate and fluxes of polar pollutants in a complex river catchment is difficult using routine monitoring procedures such as infrequent spot water sampling. As this study has demonstrated, metaldehyde is a highly stochastical pollutant due to application times and rates of slug pellets, land use and the influence of rainfall. Spot sampling (every 2 or 4 weeks) can miss pollution inputs, as there is no information on the environmental status of the river between these sampling events. A solution to this is higher frequency monitoring or through the use of automated time triggered sampling devices, however, this approach is expensive. ${ }^{15}$ Furthermore, these 
automated type samplers can only be used at secure locations due to vandalism and theft considerations.

In recent years there has been an increased interest in the use of passive sampling devices to overcome some of the above shortcomings of spot sampling procedures. Work in this area for detecting and measuring a wide range of key substances is already proving successful and leading to a better knowledge of the sources and transport of pollutants within surface water systems. ${ }^{19,33,40,41}$ Additionally, there have been a number of publications highlighting their benefits within investigative monitoring activities within the remit of the European Union's Water Framework Directive and other regulatory water quality monitoring programmes ${ }^{42,43}$ As shown in our study, key to the acceptability of the passive sampling approach by regulators and other end-users is an improved understanding of the comparability of different sampling strategies (spot, event triggered or passive) particularly for pollutants (e.g. acidic herbicides, metaldehyde) that are present episodically in river catchments. ${ }^{44}$

An additional use of passive samplers is to generate TWA concentrations that can be used in combination with in situ flow data to estimate monthly or annual fluxes of specific pollutants. ${ }^{33}$ This information can be used to better inform environmental risk assessments at the catchment scale. Furthermore, deploying passive samplers at the intake of water supply works could be beneficial in estimating annual loads of pollutants entering the plant. Such an approach is being used effectively by South West Water Ltd. for acidic herbicides at a works on the River Exe (personal communication). The data obtained is proving to be useful in aiding the operability of the treatment processes, such as when to regenerate the granular activated carbon beds.

\section{Conclusions}

This paper is one of the first publications to show how the concentrations of metaldehyde in two different river catchments are affected by the application period of slug pellets and after rainfall events. Both spot water sampling and passive sampling techniques were able to effectively monitor stochastic inputs of the molluscicide. In many instances, however, the concentration of metaldehyde in spot water samples was below the LoQ of the analytical method. The techniques gave contrasting, yet comparable, information on pollution events in the catchments. However, comparing directly the concentrations derived from these methods is difficult.

There are benefits in using passive samplers to further the understanding of sources and transport of polar pollutants within riverine systems. For example, TWA values have the potential to be used to generate more meaningful pollutant data to check against annual average environmental quality standards (EQS) within the European Union's Water Framework Directive. Furthermore, TWA concentrations (e.g. collected over a 14-day interval) rather than infrequent spot water sampling measurements can be beneficial when assessing the advantages of additional farm support measures, financial incentives and impacts of environmental remediation strategies (e.g. substitution of metaldehyde with ferric phosphate). Such time-weighted data on concentrations could be included in biogeochemical transport models such as the INCA-contaminants. Application of this model has recently been described for metaldehyde by Lu et al. ${ }^{27}$

Some knowledge gaps still remain, as passive samplers such as the Chemcatcher ${ }^{\circledR}$ can only measure average concentrations over time rather than real-time sporadic concentrations in the aquatic environment. Additionally, passive samplers cannot measure peak concentrations of pollutants within an environmental system. When concentrations were elevated in the river there is some evidence that the Chemcatcher ${ }^{\circ}$ can overestimate the TWA concentration. Although this is not an ideal situation, making environmental decisions on these measurements, however, is risk limited for water supply companies and regulators. In order to obtain more robust TWA data a further understanding is needed on desorption and uptake mechanisms of metaldehyde using the Chemcatcher ${ }^{\circ}$, as well as a comparative study against on-line sampling techniques. Despite these concerns, the Chemcatcher ${ }^{\circ}$ can provide further 
information for catchment management strategies, particularly at locations where surface water is abstracted for potable supplies.

\section{Acknowledgements}

This work was part funded by the Natural Environment Research Council (NERC) as an iCASE award (NE/L009145/1) to Glenn Castle. We acknowledge United Utilities plc for allowing us access to the River Dee catchment data. We thank Jeanette Williams (United Utilities plc) for assistance in carrying out the River Dee field trial. We acknowledge Gareth Foulkes and David Jones (Welsh Dee Trust) for facilitating the deployment and retrieval of the passive samplers and for the collection of spot water samples from the River Dee. We thank the staff at Affinity Water Ltd. (Shaun Dowman and Alister Leggatt) and Thames Water (Joanna Clint and Dinah Hillier) for financial support, facilitating the field trials and analysis of spot water samples. Thanks also to Nick Palin and Sarah Wigley (Westcountry Rivers Trust) for provision of the land use and location maps.

\section{References}

1 M. Bieri, The environmental profile of metaldehyde, in Slugs \& Snails: Agricultural, Veterinary \& Environmental Perspectives, ed. G. B. J. Dussart, British Crop Protection Council, Farnham, Editon edn., 2003, pp. 255-260.

2 L. C. Simms, J. J. C. Dawson, G. I. Paton and M. J. Wilson, Identification of environmental factors limiting plant uptake of metaldehyde seed treatments under field conditions, Agric. Food. Chem., 2006, 54, 3646-3650.

3 Metaldehyde Stewardship Group, MSG resources. https://www.getpelletwise.co.uk/wp-content/uploads/2017/05/HR-A2-poster-revisedSept_2011.pdf, 2018.

4 FERA, http://pusstats.fera.defra.gov.uk/myindex.cfm, Accessed February, 2018.

5 D. B. Green, Managed applications of molluscicides for slug control in winter wheat, Brighton Crop Protection Conference: Pests \& Diseases - 1996, Vols 1-3, 1996.

6 PPDB: Pesticide Properties DataBase, http://sitem.herts.ac.uk/aeru/ppdb/en/index.htm, Accessed February, 2018.

7 Y. Ma, X. Wu, Z. Zheng, Y. Yang, C. Wang, H. Zhang and L. Meng, Dissipation and evaluation of metaldehyde residues in cabbage grown in open fields, in Renewable and Sustainable Energy, Pts 1-7, eds. W. Pan, J. X. Ren and Y. G. Li, 2012, vol. 347-353, pp. 1987-1993.

8 P. Kay and R. Grayson, Using water industry data to assess the metaldehyde pollution problem, Water Environ. J., 2014, 28, 410-417.

9 G. D. Castle, G. A. Mills, A. Gravell, L. Jones, I. Townsend, D. G. Cameron and G. R. Fones, Review of the molluscicide metaldehyde in the environment, Environ. Sci.: Water Res. Technol., 2017, 3, 415-428.

10 S. Gillman, P. Brown, D. Burgess, B. Bickle, A. Zyndul and C. Chapman, Pesticides in the river ugie-developing a catchment management approach to protect a drinking water source, Proceedings of Crop Protection in Northern Britain, 2012.

http://www.sipr.ac.uk/CPNB/Index and Proceedings 2012.pdf

11 Council Directive 98/83/EC of 3 November 1998 on the quality of water intended for human consumption, Official Journal of the European Communities L 330, 1998, pp. 32-54.

12 R. Busquets, O. P. Kozynchenko, R. L. D. Whitby, S. R. Tennison and A. B. Cundy, Phenolic carbon tailored for the removal of polar organic contaminants from water: A solution to the metaldehyde problem?, Water Res., 2014, 61, 46-56.

13 Metaldehyde Stewardship Group, MSG guidelines, https://www.getpelletwise.co.uk/home/msg-guidelines/, 2018.

14 B. Speiser and C. Kistler, Field tests with a molluscicide containing iron phosphate, Crop Prot., 2002, 21, 389-394. 
15 A. Davey, T. Hall, J. Horn, J. Jönsson and R. Keirle, Evidence Review of Catchment Strategies for Managing Metaldehyde, UK Water Industry Research, 2014.

https://www.ukwir.org/reports/13-DW-14-7/66786/Evidence-Review-of-CatchmentStrategies-for-Managing-Metaldehyde

16 B. Vrana, G. A. Mills, I. J. Allan, E. Dominiak, K. Svensson, J. Knutsson, G. Morrison and R. Greenwood, Passive sampling techniques for monitoring pollutants in water, TrAC, Trends Anal. Chem., 2005, 24, 845-868.

17 R. Lohmann, K. Booij, F. Smedes and B. Vrana, Use of passive sampling devices for monitoring and compliance checking of POP concentrations in water, Environ. Sci. Pollut. Res., 2012, 19, 1885-1895.

18 D. A. Alvarez, J. D. Petty, J. N. Huckins, T. L. Jones-Lepp, D. T. Getting, J. P. Goddard and S. E. Manahan, Development of a passive, in situ, integrative sampler for hydrophilic organic contaminants in aquatic environments, Environ. Toxicol. Chem., 2004, 23, 1640-1648.

19 P. C. Van Metre, D. A. Alvarez, B. J. Mahler, L. Nowell, M. Sandstrom and P. Moran, Complex mixtures of Pesticides in Midwest US streams indicated by POCIS time-integrating samplers, Environ. Pollut., 2017, 220, 431-440.

20 J. K. Challis, M. L. Hanson and C. S. Wong, Development and calibration of an organic-diffusive gradients in thin films aquatic passive sampler for a diverse suite of polar organic contaminants, Anal. Chem., 2016, 88, 10583-10591.

21 C.-E. Chen, H. Zhang, G.-G. Ying and K. C. Jones, Evidence and recommendations to support the use of a novel passive water sampler to quantify antibiotics in wastewaters, Environ. Sci. Technol., 2013, 47, 13587-13593.

22 R. Guibal, R. Buzier, A. Charriau, S. Lissalde and G. Guibaud, Passive sampling of anionic pesticides using the Diffusive Gradients in Thin films technique (DGT), Anal. Chim. Acta, 2017, 966, 1-10.

23 B. Petrie, A. Grayell, G. A. Mills, J. Youdan, R. Barden and B. Kasprzyk-Hordern, In situ calibration of a new chemcatcher configuration for the determination of polar organic micropollutants in wastewater effluent, Environ. Sci. Technol., 2016, 50, 9469-9478.

$24 \mathrm{~K}$. Booij, B. Vrana and J. N. Huckins, Theory, modeling and calibration of passive samplers used in water monitoring, in Passive Sampling Techniques in Environmental Monitoring, eds. R. Greenwood, G. A. Mills and B. Vrana, Elsevier, 2007, pp. 146-169.

25 G. D. Castle, G. A. Mills, A. Bakir, A. Gravell, M. Schumacher, I. Townsend, L. Jones, R. Greenwood, S. Knott and G. R. Fones, Calibration and field evaluation of the Chemcatcher (R) passive sampler for monitoring metaldehyde in surface water, Talanta, 2018, 179, 57-63.

26 United Utilities, Catchment management, https://www.unitedutilities.com/corporate/responsibility/environment/catchmentmanagement/, Accessed February 2018.

27 Q. Lu, P. G. Whitehead, G. Bussi, M. N. Futter and L. Nizzetto, Modelling metaldehyde in catchments: a River Thames case-study, Environ. Sci.: Processes Impacts, 2017, 19, 586-595.

28 Rae, Alasdair (2017): A Land Cover Atlas of the United Kingdom (Maps). Figshare. Retrieved from

https://figshare.com/articles/A Land Cover Atlas of the United Kingdom Maps /521995 $\underline{6 / 1}$

29 M. Schumacher, G. Castle, A. Gravell, G. A. Mills and G. R. Fones, An improved method for measuring metaldehyde in surface water using liquid chromatography tandem mass spectrometry, MethodsX, 2016, 3, 188-194.

$30 \mathrm{~J}$. N. Huckins, J. D. Petty and K. Booij, Monitors of organic chemicals in the environment: Semipermeable membrane devices, Springer Science+Business Media, LLC, New York, 2006.

31 D. Fernandez, E. L. M. Vermeirssen, N. Bandow, K. Munoz and R. B. Schafer, Calibration and field application of passive sampling for episodic exposure to polar organic pesticides in streams, Environ. Pollut., 2014, 194, 196-202. 
32 S. A. Morrison, B. Luttbeg and J. B. Belden, Comparisons of discrete and integrative sampling accuracy in estimating pulsed aquatic exposures, Environ. Pollut., 2016, 218, 749-756.

33 Z. L. Zhang, M. Troldborg, K. Yates, M. Osprey, C. Kerr, P. D. Hallett, N. Baggaley, S. M. Rhind, J. J. C. Dawson and R. L. Hough, Evaluation of spot and passive sampling for monitoring, flux estimation and risk assessment of pesticides within the constraints of a typical regulatory monitoring scheme, Sci. Total Environ., 2016, 569, 1369-1379.

34 J. Criquet, D. Dumoulin, M. Howsam, L. Mondamert, J. F. Goossens, J. Prygiel and G. Billon, Comparison of POCIS passive samplers vs. composite water sampling: A case study, Sci. Total Environ., 2017, 609, 982-991.

35 A. J. Novic, D. S. O'Brien, S. L. Kaserzon, D. W. Hawker, S. E. Lewis and J. F. Mueller, Monitoring herbicide concentrations and loads during a flood event: A comparison of grab sampling with passive sampling, Environ. Sci. Technol., 2017, 51, 3880-3891.

36 I. J. Allan, K. Booij, A. Paschke, B. Vrana, G. A. Mills and R. Greenwood, Field performance of seven passive sampling devices for monitoring of hydrophobic substances, Environ. Sci. Technol., 2009, 43, 5383-5390.

37 I. J. Allan, K. Booij, A. Paschke, B. Vrana, G. A. Mills and R. Greenwood, Short-term exposure testing of six different passive samplers for the monitoring of hydrophobic contaminants in water, J. Environ. Monit., 2010, 12, 696-703.

38 V. Fauvelle, S. L. Kaserzon, N. Montero, S. Lissalde, I. J. Allan, G. Mills, N. Mazzella, J. F. Mueller and K. Booij, Dealing with flow effects on the uptake of polar compounds by passive samplers, Environ. Sci. Technol., 2017, 51, 2536-2537.

39 K. Booij, N. L. Maarsen, M. Theeuwen and R. van Bommel, Method to account for the effect of hydrodynamics on polar organic compound uptake by passive samplers, Environ. Toxicol. Chem., 2017, 36, 1517-1524.

$40 \mathrm{~S}$. Lissalde, N. Mazzella and P. Mazellier, Polar organic chemical integrative samplers for pesticides monitoring: Impacts of field exposure conditions, Sci. Total Environ., 2014, 488, 188196.

41 G. Poulier, S. Lissalde, A. Charriau, R. Buzier, K. Cleries, F. Delmas, N. Mazzella and G. Guibaud, Estimates of pesticide concentrations and fluxes in two rivers of an extensive French multiagricultural watershed: application of the passive sampling strategy, Environ. Sci. Pollut. Res., 2015, 22, 8044-8057.

42 G. Poulier, S. Lissalde, A. Charriau, R. Buzier, F. Delmas, K. Gery, A. Moreira, G. Guibaud and N. Mazzella, Can POCIS be used in Water Framework Directive (2000/60/EC) monitoring networks? A study focusing on pesticides in a French agricultural watershed, Sci. Total Environ., 2014, 497, 282-292.

43 L. Jones, J. Ronan, B. McHugh, E. McGovern and F. Regan, Emerging priority substances in the aquatic environment: a role for passive sampling in supporting WFD monitoring and compliance, Anal. Methods, 2015, 7, 7976-7984.

44 I. B. Roll and R. U. Halden, Critical review of factors governing data quality of integrative samplers employed in environmental water monitoring, Water Res., 2016, 94, 200-207. 